\title{
PARADIGMAS GLOBAIS E SUAS IMPLICAÇÕES NO ESPAÇO URBANO: A AGENDA HEGEMÔNICA DA SUSTENTABILIDADE NAS ESFERAS PÚBLICA E PRIVADA
}

\author{
FERNANDO PINTO RIBEIRO ${ }^{1}$ \\ Universidade de São Paulo
}

Resumo: Este artigo tem por objetivo circunscrever as articulações entre o território urbano e os chamados paradigmas sociais nascentes no processo de globalização. Nesta abordagem, trata-se de visualizar a emergência de um paradigma ambiental crítico às mazelas do crescimento econômico e de outro paradigma neoliberal, que alicerça uma nova ordem econômica global em prol da aceleração deste crescimento. A despeito de suas contradições, ambos se articulam no bojo de uma agenda ambiental hegemônica que erige a noção de sustentabilidade como novo marco de pensamento da civilização e da cidade. A partir de uma matriz discursiva dominante, tal noção penetra nos campos de produção da cidade por intermédio de inúmeros canais de articulação - e isso leva em conta as ações do mercado e de organismos supranacionais que passam a interferir nos mecanismos de gestão e planejamento da esfera pública local. Nesse sentido, as Agendas 21 locais, bem como os documentos produzidos pelo Banco Mundial e outros organismos de planejamento, se juntam aos chamados "mercados verdes" do setor imobiliário e da construção e, assim, instituem relevante engrenagem de transformação da cidade contemporânea, em suas múltiplas escalas e espaços.

Palavras-chave: Planejamento Urbano; Sustentabilidade; Mercados Verdes; Neoliberalismo

\section{GLOBAL PARADIGMS AND THEIR IMPLICATIONS IN THE URBAN SPACE: THE HEGEMONIC AGENDA OF SUSTAINABILITY IN THE PUBLIC AND PRIVATE SPHERES}

Abstract: This paper analyses the relation between urban territory and the so-called social paradigms that emerged during the process of the globalization. In this approach, it means to see the emergence of, on the one hand, a environmental paradigm which is critical to the dilemmas of economic growth

\footnotetext{
${ }^{1}$ Geógrafo e mestre em Geografia pela UFSC; doutorando em Planejamento Urbano e Regional na FAU/USP. Contato: nandopribeiro@yahoo.com.br.
} 
and, on the other, a neoliberal paradigm that act as a foundation of a new global economic order in favor of boosting growth. Despite these contradictions, both paradigms merge together in a hegemonic environmental agenda which promotes the notion of sustainability as the hallmark of thinking about civilization and the city. Having turned into a mainstream discourse, the notion of sustainability influences the production of the city through several means, including the actions of market player sand the international organisms that interfere in the process of public urban governance. Thus, the local Agenda 21, the reports elaborated by the World Bank and other international organisms, as well as the strategies used in the green projects of the real estate and construction sectors, all constitute a web of agents that transform the contemporary city in its multiple scales and spaces.

Keywords: Urban Planning; Sustainability; Green Market; Neoliberalism.

\section{Introdução}

A proposta analítica deste artigo aponta para o reconhecimento do neoliberalismo e do ambientalismo como paradigmas sociais que surgem à luz de uma nova contemporaneidade, datada a partir da década de 1970. Em uma década de intensa efervescência cultural e social, tais paradigmas se projetam com base num discurso crítico direcionado ao modelo de desenvolvimento fordista, ainda que tais críticas estejam amparadas por visões diametralmente opostas. Se, de um lado, questiona-se a viabilidade daquele modelo como mantenedor da lucratividade empresarial e como promotor da capacidade de inovação e mitigação das crises internas ao sistema, por outro, ampliam-se os debates a respeito das implicações da economia fordista para os ecossistemas planetários.

Com efeito, ambas as correntes de pensamento se fortalecem ao longo do processo de globalização e fundam modelos interpretativos de explicação da realidade que passam a induzir novas práticas de produção do território. Suas contradições serão gradativamente deixadas de lado para constituir um novo marco de reorientação social permeado pelo conceito de sustentabilidade, cuja subjetividade cede lugar às visões que buscam objetivá-la segundo os ditames da economia capitalista. Ele consistirá de formulações agregadas a uma matriz discursiva hegemônica do pensamento ambiental que, apesar de abraçar diretrizes progressistas e abrangentes no tocante à problemática do meio ambiente, legitima o apelo ao crescimento econômico e às práticas mercantis embasadas pela livreiniciativa. Para as cidades, a marca sustentável estará amparada neste discurso hegemônico que incentiva a adequação delas às dinâmicas globais - de onde provém a busca por se tornar uma "cidade global" -, vinculando-se à gestão empreendedora e às práticas competitivas dos agentes econômicos urbanos.

Diante disso, o intuito deste artigo é delinear uma discussão que desvende os canais de articulação desta agenda hegemônica, com vistas a empreender uma leitura acerca das engrenagens que movimentam a construção da cidade contemporânea. Para tanto, a abordagem apontará as principais instituições que 
promulgam o discurso da sustentabilidade na esfera política local, bem como delineará os principais traços que o mercado da sustentabilidade cria, dentre eles os grandes empreendimentos imobiliários ditos "sustentáveis", ou os chamados écoquartiers que se disseminam na França a partir da década de 1990. Tal esforço analítico visa, assim, demonstrar os indicativos espaciais que evidenciam a "cidade sustentável" como nova categoria de compreensão do território.

\section{Paradigmas globais e a constituição da matriz hegemônica da sustentabilidade urbana}

A teoria dos paradigmas de Kuhn (1970), embora se desenvolva no campo da Filosofia da Ciência, serve para elucidar os significados que o neoliberalismo e o ambientalismo adquirem no limiar da década de 1980. Um paradigma, no sentido exposto por Kuhn, implica a incomensurabilidade e acriticismo das ideias que o compõem, ao ponto em que estabeleçam anomalias e inconsistências que sinalizem um período de crise e substituição por um novo paradigma. Este resgate em Thomas Kuhn busca elucidar a dimensão exercida pelo espectro neoliberal e pelo discurso ambiental como entidades paradigmáticas, não no sentido integral exposto por Kuhn, mas por elaborarem visões de mundo e influírem decisivamente na constituição de um ideário específico construído nos campos acadêmico e profissional.

Desse modo, o neoliberalismo aparece como paradigma renovado de caráter quase inquestionável, pois fundamenta ideologicamente os impulsos da globalização através da técnica, da fluidez, do livre mercado, da abertura e desregulamentação das economias nacionais, do alargamento da esfera privada, do empreendedorismo em suas múltiplas escalas, da supremacia do capital financeiro. Também se considera o ambientalismo como um paradigma, na medida em que a deterioração ambiental assume repercussões planetárias, sobretudo como objeto de crescente debate e politização elevado a uma questão que provocará a formação de diferentes grupos, de moderados a radicais, a externarem suas inseguranças e ameaças trazidas pela poluição atmosférica e hídrica e pela extração massiva de recursos naturais para dar sustentação à emergente sociedade de consumo. $\mathrm{O}$ paradigma ambiental, assim constituído, reforça a visão de unidade entre o homem e a natureza, em substituição àquela perspectiva que coloca a natureza como meio para o desenvolvimento das ações humanas.

O avanço contemporâneo destes dois paradigmas significa, em outras palavras, o avanço paralelo de arcabouços conceituais ideologicamente concebidos na esteira de um novo período. Paralelo na medida em que ambos se fortalecem e se reafirmam sem bases e diretrizes comuns, cujo antagonismo essencial se encontra em distintos projetos civilizatórios. Convém ressaltar que o movimento ambiental 
se sistematiza de modo a negar o crescimento ilimitado que alimenta padrões insustentáveis de produção e consumo; aspecto que, por outro lado, no neoliberalismo é incentivado, já que ele se coloca como fomentador do uso indiscriminado de recursos naturais e gerador incessante de externalidades socioambientais oriundas da atividade econômica.

Entretanto, este distanciamento não encontrará justificativa no momento em que ambos os paradigmas rompem ou ignoram tais antagonismos de base e formulam um viés paradigmático aglutinador e consensual, medido por um conjunto de ideias sintetizadas pela noção de sustentabilidade, embora outros conceitos relativos gravitem em torno deste. Esta noção de sustentabilidade logo adquire um teor estratégico, pois se inscreverá no âmbito dos agentes do mercado sob a tintura da pactuação, do consenso e de um senso de responsabilidade e comprometimento por parte das empresas e dos governos com a problemática ambiental. Com efeito, este discurso supõe que os mecanismos econômicos de mercado e as esferas de poder governamental fomentem cenários de menor impacto e maior conservação ambiental, por intermédio de mudanças tecnológicas na escala energética e métodos de gestão mais eficientes dos resíduos e da extração de recursos. O campo dos conflitos ambientais adquire um teor economicista, expressando a articulação entre agentes econômicos globais e o discurso ambiental, o que não necessariamente envolve o movimento ambientalista em si.

Neste ponto deve-se enfatizar, portanto, que a posterior convergência que caracteriza tal contexto dos paradigmas ambiental e neoliberal deixa registros marcantes no território urbano, como se este expusesse a realidade objetiva que ambos imprimem no contexto social. Assim, a crescente urbanização condiciona a institucionalização de uma questão ambiental - na medida em que a concentração demográfica nos grandes centros, os efeitos da dispersão urbana, a eclosão de conflitos por acesso a recursos naturais, a falta de infraestrutura para atender às crescentes demandas, a poluição e o aumento do consumo de mercadorias, em conjunto, atuam como vetores de uma problemática sobre o uso e a ocupação do solo, engrenam um movimento de ambientalização das políticas públicas e contribuem para o fortalecimento da racionalidade ambiental.

Essas são preocupações que eclodem em meio a um forte crescimento da economia mundial, cuja repercussão urbana pode ser verificada, sobretudo, na acelerada suburbanização das cidades norte-americanas e na industrialização significativa ocorrida nos países periféricos, ambos fenômenos que compõem essencialmente o modelo de dispersão urbana engrenado pelo automóvel. Essa economia dependente de combustíveis fósseis possibilitará e sustentará a brutal expansão do capitalismo na esteira da globalização neoliberal, de modo a permitir que novos territórios sejam incorporados à dinâmica econômica global. Isso significará a ampliação das rupturas entre o mundo do trabalho e o do capital; a inversão de poderes no interior do espectro político mundial; a derrocada do espaço 
público em decorrência do domínio incisivo da iniciativa privada sobre terras e meios de produção e, efetivamente, a intensificação da exploração da natureza para fins econômicos. A realidade objetiva inscrita nestas rupturas faz emergirem antigas e novas preocupações concernentes ao paradigma ambiental, pois revigora a crítica antissistema e instaura o conceito de sustentabilidade. O teor destes eventos associados à radicalização da economia de mercado e suas consequências sociais apontará o espaço urbano como palco principal, de modo a reestruturá-lo no que se compreende como a cidade neoliberal.

Os contextos social, econômico e cultural da globalização financeira configuram esta cidade que fomenta a perspectiva do pós-modernismo, que busca seu conteúdo global e seu viés empreendedor. Como Harvey (2006) atesta, o administrativismo ou gerenciamento urbano cede ao modelo de empreendedorismo quando o Estado perde sua capacidade de controle sobre o capital, na medida em que este encontra com maior facilidade terrenos mais férteis para se expandir. A competição típica da empresa capitalista é estendida ao setor público e será este o modelo de gestão que começa a se interpor nos órgãos de governo e no planejamento desde então.

Dessa forma, o empreendedorismo urbano expressa na escala local o que o imperativo do crescimento econômico impõe aos Estados Nacionais. Convém mencionar que a problemática ambiental urbana, sobretudo nos países periféricos, se agudiza em consonância às exigências deste crescimento econômico ao qual o empreendedorismo está imbricado. Restringindo esta análise aos países periféricos, serão as pressões por terras e a tecnificação do meio rural e urbano que passam a emoldurar um território com focos de modernização e riqueza em meio a aglomerações precárias e de baixa renda. Em ambas as facetas deste território impõem-se questões ambientais que estarão evidenciadas, por exemplo, nas contradições sociais associadas à dinamização dos fluxos migratórios e à ocupação inadequada do solo urbano, ou no alargamento do rodoviarismo e na dominação da terra urbana. Tais elementos passam a compor o debate ambiental contemporâneo que se desenvolverá em fóruns, conferências e campos de discussão política, nos quais começam a ser instituídas as receitas que devem reorientar as incertezas que emanam do território. Os canais de discussão estarão mais ou menos vinculados aos pressupostos inseridos nos consagrados documentos instituídos pela ONU e pelo Banco Mundial - como o Relatório Bruntland e a Agenda 21 -, de modo a compor um discurso hegemônico através do qual a sustentabilidade converte-se em horizonte para praticamente todos os males urbanos atuais, abrangendo desde questões referentes aos marcos regulatórios de uso e ocupação até àquelas sociais e econômicas, como o combate ao desemprego, a qualificação de mão-de-obra, a provisão de infraestrutura etc. 


\section{Canais de articulação da agenda hegemônica na esfera pública: Banco Mundial, ICLEI e a gestão urbana empreendedora}

O núcleo discursivo que substancia a concepção sustentável para as cidades fundamenta uma uniformidade oculta na diversidade de interpretações que compõem o discurso hegemônico da sustentabilidade. Em outras palavras, consiste que tal concepção se reverbera em uma conjuntura de interpretações que divergem no plano do método e da abordagem, mas que se interconectam por intermédio de determinados nexos que representam o cerne do seu discurso. Basicamente, se configura em um eixo de análise que leva em consideração o combate às mazelas sociais e ambientais em sua complexidade, sob a condução de um arcabouço institucional que favoreça as práticas mercantis em sua plenitude - sem entraves - e que reoriente as escalas de poder de modo a fortalecer os governos locais. Em outros termos, deve-se pensar um desenvolvimento que leve em conta a relação interdependente entre sistema econômico, meio ambiente e sociedade e que escore este tripé em aparatos institucionais sólidos e democráticos, alicerçados pela descentralização do poder político.

Todavia, tal apelo progressista merece redobrada atenção, tendo em vista os métodos nos quais estarão baseados os modelos de intervenção urbana sustentável, pois repercutem os processos econômicos atrelados ao modelo neoliberal. Isso significa que o discurso nascente começa a configurar um processo de articulação entre o paradigma ambiental crítico e o paradigma do livre mercado, obscurecendo, de um lado, as contradições que emanam de ambas as racionalidades e, de outro, as facetas positivas que emergem da relação economia-ambiente. Convém aqui reforçar esta argumentação a partir de alguns documentos ligados ao Banco Mundial.

Mais atual, o intitulado Eco ${ }^{2}$ Cities Guide - Ecological Cities as Economic Cities, de Moffatt et. al. (2012), como o próprio título atesta, constitui-se num guia para o planejamento segundo a égide do Banco Mundial. Prevalece neste documento o termo Ecocities, embora durante todo o texto o mesmo esteja amparado pelo termo sustentável, como é possível observar em várias passagens.

As Ecocities implicam a melhora do bem-estar dos cidadãos e da sociedade através de um processo de gestão e planejamento urbano integrado, aproveitando os benefícios que o sistema ecológico fornece e, ao mesmo tempo, protegendo-o e garantindo-o às futuras gerações. Seu potencial econômico cria valor e oportunidades para cidadãos, empresários e sociedade a partir de uma atividade econômica sustentável baseada na produção, na inclusão e na eficiência (MOFFATT et. al., 2012, 


\section{p.7, tradução nossa).}

Mais adiante, o texto sublinha que as Ecocities são construídas pelo que chamam de "sinergia" e "interdependência" entre sustentabilidade econômica e ambiental. Para isso, argumenta que, tanto em países desenvolvidos como nos em desenvolvimento, existem demonstrações de cidades inovadoras no fortalecimento da capacidade econômica a partir do manejo adequado dos recursos ambientais. Consequentemente, segundo o relatório, as cidades viabilizam maior qualidade de vida aos cidadãos, melhoram seu potencial competitivo e conseguem atrair mais investimentos (MOFFATT et. al. 2012). Os autores prosseguem afirmando que tal concepção não implica um modelo fragmentado de práticas ambientais, mas encoraja uma análise holística que abraça soluções integradas pautadas por um sólido processo participativo em distintos níveis de decisão.

Contraditoriamente, a cidade que ilustra a capa do relatório será Curitiba e, ao final, leem-se palavras do ex-prefeito que enfatizam a "aptidão criadora e inspiradora da cidade, conclamando outras ao desafio do século XXI: a sustentabilidade". Não de outra forma, este exemplo torna-se emblemático acerca da carga ideológica que o discurso hegemônico adquire, emprestando as mazelas do desenvolvimento à construção simbólica de um cenário de eficácia e perfeição. Veem-se, nesse sentido, as demonstrações de um novo protagonismo da cidade com as demandas do mundo contemporâneo, mediante diretrizes que passam a imprimir o compromisso do agente local frente à sustentabilidade preconizada pela agenda hegemônica. Como observado neste documento acerca das Ecocities, tal compromisso opera por meio da identificação de win-winsituations e leva em conta pactos voluntários, de acordo com os interesses de cada parte.

Esse também é o mote de outros dois relatórios sobre o tema que circunscrevem a própria visão institucional do Banco Mundial. Se intitulam A strategic view of urban and local government issues: implications for the Bank (BANCO MUNDIAL, 1999) e Cities in transition: World Bank urban and local government strategy (BANCO MUNDIAL, 2000). A matriz da visão e das ações estratégicas em direção à cidade sustentável aponta para as tendências em curso desde a década de 1980: descentralização da gestão, parcerias público-privadas e o enfoque abrangente relacionado aos aspectos econômico, ambiental e social. Em ambos os relatórios podem ser encontrados quatro elementos essenciais à cidade sustentável: livability, competitividade, boa governança e bankability. Em síntese, livability corresponde às condições relacionadas à qualidade de vida implícita ao ambiente social e ambiental urbano. A competitividade internaliza a base econômica de acordo com os níveis de emprego, renda e, especialmente, novos investimentos. As principais condicionantes apontam aos níveis de produtividade segundo a liberalização e integração dos mercados, de modo a torná-los mais competitivos. Boa governança implica a mais adequada representação dos setores da sociedade 
nos processos de decisão, transparência e integridade dos governos locais. E, por fim, bankability diz respeito a um sistema financeiro local estável e responsável, associado à maior credibilidade das municipalidades em receber novos investimentos.

A respeito das perspectivas do Banco Mundial, merece uma última consideração o trabalho elaborado por Fernando Rojas (1998) e analisado com primazia por Fabrício Oliveira (2009), intitulado Sustainable Cities. Oliveira enxerga com perspicácia os significados atrelados à concepção sustentável do Banco Mundial e correlaciona seus fundamentos ao chamado planejamento estratégico para as cidades, de Borja e Castells (1997). Na visão de Rojas, o desafio da sustentabilidade para as cidades desempenha uma relação de interdependência com a sua capacidade competitiva, pela qual ganham relevo relações de complementaridade que formulam o cerne do discurso ambiental na economia de mercado. Em outras palavras, incute-se a importância seminal do processo competitivo das empresas como fundamento norteador das políticas urbanas, aspecto inevitável que exige, mediante visões estratégicas, compatibilizar os desejos do crescimento com o principio de sustentabilidade. Esta é uma relação expressa pelo modelo empreendedor de gestão e os mecanismos que o poder local explora para fortalecer sua competitividade são inúmeros, dentre eles, a redução de custos para empresas, a oferta de terrenos, a infraestrutura etc. (HARVEY, 2006).

O que deve ser destacado a partir do trabalho de Rojas é que nele se resguarda uma interpretação ressonante dentre o rol de trabalhos que tratam acerca da estratégia sustentável, cuja tendência é apontá-la como novo atributo que se arrola ao movimento de competição intraurbana. Ela se transforma em outro tipo de vantagem comparativa que influirá tanto no fluxo de investimentos quanto nas ofertas de consumo. Em se tratando de investimentos, as Sustainable Cities, de Rojas, são os locais de descentralização administrativa, parcerias público-privadas, boa governança, consenso, experimentação, desenvolvimento institucional, desregulamentação etc. Em suma, quase nada de inovador às outras contribuições do Banco Mundial. Mais adiante, segundo Oliveira, Rojas lista recomendações para a gestão urbana com vistas à atração de investimentos, que englobam:

Reformas legais que facilitem a participação das empresas e da sociedade civil nos projetos da cidade, documentação e disseminação das "boas", "melhores" práticas dos governos locais, desenvolvimento institucional que facilite a "harmonização das prioridades da cidade com agendas e políticas nacionais", e construção de "canais participativos para desenvolver alianças capazes de combater a pobreza assim como a marginalidade social, política e econômica" (OLIVEIRA apud ROJAS, p. 206, 2009). 
Em Rojas e nos outros documentos do Banco Mundial aparecem claramente as interpretações que se aglutinam ao discurso sustentável predominante, verificado como requisito ao processo competitivo no qual a cidade estará "inevitavelmente" inserida, segundo as assertivas liberais. Tais interpretações acompanham as diretrizes construídas no contexto das conferências ambientais, não obstante, elaborem uma resposta própria e institucional do Banco. Com base nestes elementos se interpõe uma visão neoliberal da estratégia sustentável do desenvolvimento em que cada cidade estaria mais ou menos adequada às articulações da economia global.

Igualmente, esta visão encontrará outros mecanismos de dispersão, dentre eles merece destaque o papel exercido pelo Internacional Council for Local Environmental Iniciatives (ICLEI), também reconhecido como Local Governments for Sustainability. Segundo a própria visão estratégica da instituição, o ICLEI corresponde a um movimento internacional de governos locais associados, cuja finalidade é desenvolver políticas alicerçadas na Agenda 21, o que inclui procedimentos de consultoria, treinamento, troca de informações e suporte aos governos locais com vistas a implementar o "desenvolvimento sustentável". Assim, o ICLEI pode ser considerado um dos movimentos mais significativos na consolidação da agenda hegemônica na esfera política local, exercendo forte papel descentralizador de acordo com os princípios vinculados à Agenda 21.

Portanto, como o Banco Mundial, o ICLEI constitui-se em um agente definidor e determinante da agenda hegemônica. Há, entretanto, um vínculo muito mais próximo e complementar entre os eventos ambientais e o ICLEI, pelo qual este se arrola ao propósito de consolidar iniciativas incorporadas pelas Agendas 21 locais.

Nesse sentido, o ICLEI irá espelhar a interpretação tradicional da estratégia sustentável derivada da ECO-92, incorporando em suas iniciativas um rol de formulações posteriores intrínsecas à matriz hegemônica, reverberando-a para mais de 1200 municipalidades em 70 países, de acordo com seu relatório anual (ICLEI, 2012). Os pressupostos básicos contidos nas ações do ICLEI são elucidados com maior precisão em dois documentos produzidos pela própria instituição: o ICLEI Stratetig Plan 2010-2015 (2011) e o 2006 year in review - local action moves the world (2006).

O primeiro documento demonstra os objetivos aos quais os poderes locais devem se alinhar em face aos desafios da "cidade sustentável". Por esta visão estratégica, o primeiro objetivo consiste na integração das políticas sustentáveis, o que significa o fortalecimento de políticas e a criação de ferramentas e de modelos de inovação baseados nas demandas da Agenda 21; por exemplo, desenvolver indicadores de perfomance de sustentabilidade e expandir a consciência e a transparência a respeito da pegada ecológica da cidade. Em seguida, surge a preocupação com a eficiência da cidade no manejo dos recursos naturais, cujas ações competem integrar pesquisas em tecnologia sustentável e promover 
programas específicos instituídos pelo ICLEI, como o Eco-Budget e o Ecoefficiency. O terceiro objetivo é encorajar cidades para o compromisso da biodiversidade urbana, de acordo com programas específicos, mas também sob aqueles de tutela do ICLEI - sobretudo o Biodiver Cities e o Cities in Biodiversity Hotspots. Na mesma direção, o quarto objetivo conclama a redução das emissões de gases poluentes por meio de políticas e investimentos em infraestrutura, além de outros programas pilotos, como o Cities for Climate Protection. O quinto objetivo diz respeito ao fortalecimento do que denominam de comunidades resilientes, cujo significado está em diminuir os graus de vulnerabilidade das cidades para os riscos aos quais estão mais expostas, sejam econômicos ou naturais. Segundo a própria visão estratégica do ICLEI, boa parte dos objetivos anteriores depende do sexto objetivo, que consiste em priorizar os investimentos em infraestruturas "verdes", o que comporta não somente o componente tecnológico do equipamento urbano, mas a maneira como esta tecnologia é planejada e integrada para criar um modelo mais funcional possível. O sétimo objetivo vislumbra desenvolver e viabilizar uma economia local fundada sobre princípios sustentáveis, mediados por empresas que incorporem as demandas ambientais a partir de processos de produção e consumo mais conscientes e adaptados às exigência do século XXI. Por fim, o oitavo objetivo do ICLEI é constituir, na esteira destas transformações, comunidades com altos índices de qualidade de vida onde os governos locais devem centralizar seus esforços em medidas para a boa governança, a cultura, a educação, a saúde e os espaços públicos (ICLEI, 2011).

Esses oito objetivos resumem a pauta do quinquênio 2010-2015 do ICLEI e foram descritos de forma a extrair o essencial do seu discurso. Eles orientarão diversas iniciativas promovidas pelo ICLEI, as quais podem ser verificadas no segundo documento citado anteriormente. No rol de medidas estarão incluídas, por exemplo, campanhas de proteção do clima a partir das denominadas CCP's (Cities for Climate Protection), cujas ações nas municipalidades associadas se voltam para o aprimoramento dos mecanismos de monitoramento de emissões de gases poluentes. Este exemplo do CCP serve para demonstrar como o ICLEI atua no âmbito internacional, buscando articular seus princípios às distintas conjunturas sociais, com base no intercâmbio de informações entre as cidades membro. Em torno da Agenda 21 gravitam essa e outras iniciativas que envolvem questões ligadas à segurança, governança participativa, gestão de riscos e inúmeros outros elementos do cotidiano local.

Analisando mais detidamente observa-se nas finalidades do ICLEI o mesmo arcabouço que alicerçou as premissas do desenvolvimento sustentável, o que demonstra não somente um forte alinhamento ao conteúdo da Agenda 21, mas uma cristalização dos mesmos princípios que posteriormente serão criticados na conferência Rio +20 . Aqui, o ponto que deve ser salientado é que, a despeito das iniciativas de cunho progressista como o compromisso com a biodiversidade e o 
aumento da capacidade de resiliência urbana, há um apelo incessante em torno do qualificativo sustentável como condição basilar de transformação social. Tal apelo é o mesmo que permeia a agenda hegemônica ao longo dos anos e revela, de um lado, a concepção pactuadora e consensual que demarca o paradigma ambiental neste momento e, de outro, a constituição de uma marca que deriva de todo e qualquer procedimento vinculado à estratégia sustentável. Da mesma forma, o ICLEI reitera um aspecto recorrente vinculado às ações da agenda hegemônica que consiste em dissipar sob uma mesma marca as incertezas que se interpõem ao espaço contemporâneo, não obstante as distintas viabilidades que a caracterizam. Em outras palavras, trabalha-se, por exemplo, com um ideal de qualidade de vida muito mais incerto, mas que se agrega à realidade do discurso do mesmo modo que a priorização de infraestruturas mais adequadas e menos impactantes à cidade, o que implica um grau muito maior de certeza e viabilidade. $\mathrm{O}$ apelo à qualidade de vida, da mesma forma que o princípio de liveability do Banco Mundial, imprime vigor à matriz discursiva dominante, embora sua vinculação com a práxis social ganhe traços bem menos claros do que medidas de tecnificação verde.

Portanto, enquanto outro canal de relativa importância da agenda hegemônica, o ICLEI vem complementar os pressupostos do Banco Mundial no intuito de demonstrar o sistema interpretativo que emerge na década de 1990 em torno da questão ambiental. Esse sistema comportará atores múltiplos e diversos que passam a definir os rumos da política ambiental urbana nos anos seguintes, cuja pauta está em reforçar a visão interdependente entre economia, sociedade e ambiente sob novos modos de governança, no qual a crítica social e ambiental se vê amparada por um modelo econômico mais "humanizado".

\section{A Sustentabilidade em sua dimensão de consumo: o papel do agente privado}

Ainda falta comentar sobre o valor de consumo associado à sustentabilidade urbana como outra vantagem que a destaca dentre as categorias que permeiam a gestão empreendedora e o próprio mercado. Este é um fenômeno que se dissemina rapidamente na medida em que a agenda hegemônica adquire espaço e canais de difusão, dos quais vale destacar a mídia e as agências multilaterais que influem direta e indiretamente sobre o planejamento urbano. A mídia e os mecanismos de marketing representam a consolidação dos chamados "mercados verdes" enquanto o setor da economia que cresce em grande proporção desde a década de 1990 . Na cidade esse fenômeno se direciona ao ambiente construído, desde o processo de concepção à execução dos projetos. Em outros termos, o simbolismo que emana dos princípios da agenda hegemônica constrói uma "razão" emoldurada pelo qualificativo sustentável que a torna, por si só, uma mercadoria de consumo. Se a mesma é condição e vantagem para atração de investimentos, é, igualmente, 
expressão de um mercado que cresce sob a tintura ideológica da transformação social e ambiental.

Nesse sentido, é importante esclarecer que não será apenas o empreendedorismo e as consequências que o mesmo gera na gestão das cidades os principais motes desta penetração da questão ambiental na produção urbana. $\mathrm{O}$ empreendedorismo representa apenas uma faceta do processo, caracterizado pela ação do poder público e seus mecanismos de gestão. Do que interessa, em particular, a ação do mercado - do agente privado - seja atuando de maneira independente, seja em parceria com o poder público. A literatura crítica sobre a temática parece não oferecer a mesma atenção ao papel dos promotores imobiliários privados na condução de projetos urbanos que agregam a agenda hegemônica da sustentabilidade, já eles, ao contrário, exercem função preponderante na prefiguração desta hegemonia. Refere-se aqui aos grandes consultores internacionais que irão auxiliar na elaboração dos planos estratégicos conduzidos pelo poder público, mas, sobretudo, representam o empreendedor imobiliário, a grande incorporadora, os escritórios de arquitetura e urbanismo e outros grupos empresariais da construção civil. São agentes que evocam o modelo da cidadesustentável segundo as diretrizes que a agenda hegemônica começa a constituir, cada um com suas distintas estratégias.

A década de 1990 pode ser considerada um período de acelerada expansão de projetos e planos que operam sob os pressupostos ambientais. Este fenômeno do chamado green business sinalizava, já naquela década, a emergência de um novo setor da economia com expressiva perspectiva de crescimento, sintetizado a partir dos termos "oportunidade" e "tendência". O sentido de oportunidade tem significado, de um lado, a saída que os mercados verdes passaram a constituir para muitos capitais ociosos no âmbito do processo de acumulação e, de outro, uma perspectiva nova de diferenciação no curso da economia competitiva. Visto como uma chance, o mercado da sustentabilidade começa a constituir-se como setor chave de desenvolvimento econômico em escala global e aquela oportunidade passa a fundamentar o discurso da tendência inevitável da economia para o século XXI.

A despeito da natureza do fenômeno, o importante é afirmar a relativa e crescente influência que o mesmo tem exercido nos agentes privados vinculados à indústria da construção e, para isso, basta olhar o desenvolvimento de setores da economia a ele associados, tais como: empresas de consultorias ambiental e urbana, empresas de tecnologia ambiental na construção, de certificação, de gestão ambiental ligadas ao processo da construção etc. Além disso, ao se observar com mais atenção a dimensão espacial desta influência da agenda hegemônica na configuração de novas formas urbanas em escala global, percebe-se que aquela tendência não somente existe como se fortalece anualmente, segundo as repercussões e evidências espaciais que podem ser vistas nas cidades europeias, 
norte-americanas e brasileiras, por exemplo. Na verdade, o desafio mais premente na investigação desse fenômeno reside na tentativa de dimensioná-lo e captá-lo no contexto das variabilidades existentes na complexa rede de intervenções urbanas "sustentáveis" pelo mundo, o que aqui não se ousa avaliar. No entanto, convém nesta etapa da discussão demonstrar o panorama geral do processo segundo elementos e atores importantes vinculados à indústria da construção e da concepção urbanística.

No âmbito desse dimensionamento, podemos apontar evidências interessantes nos Estados Unidos, na Europa e no Brasil, tendo em vista o grau de influência que as mesmas têm exercido no ambiente construído nestes contextos ao longo das décadas de 1990 e 2000. Nos Estados Unidos trata-se de levar em consideração, na esfera da concepção urbanística, a dispersão de intervenções baseadas na Carta do Novo Urbanismo Americano (1993), em que estão instituídos princípios para a edificação de comunidades sustentáveis (Sustainable Neighborhoods) segundo diferentes escalas de intervenção. O princípio da sustentabilidade será capturado como conceito motriz para o desenvolvimento de projetos que procuram mitigar os efeitos do padrão suburbano nos Estados Unidos que, assim, serão feitos por intermédio de projetos para novas áreas de expansão ou por planos de reestruturação urbana mediante a recuperação de áreas degradadas. Dessa forma, promotores privados vinculados ao Congress for the New Urbanism (1993) conduzirão suas ações com base em concepções que visam constituir comunidades mistas, densas, multicentralizadas, diversas em seus aspectos econômicos e sociais e, sobretudo, que possuam identidade e um senso de lugar. Os prédios devem, basicamente, estar vinculados ao seu entorno, incentivar e contribuir para a segurança e acessibilidade dos ambientes, bem como ser eficientes nos manejos dos recursos ambientais. De acordo com Keith e Del Rio (2003), baseados em artigo da Revista Time, nos cinco primeiros anos após a institucionalização do CNU já tinham sido construídos mais de 100 projetos, e outros 200 já constavam nas pranchetas dos escritórios de arquitetura. Assim, as características implícitas ao New Urbanism têm incentivado no âmbito arquitetônico e urbano a proliferação das denominadas "comunidades sustentáveis", não somente a partir das orientações da carta deste movimento urbanístico, mas também pela vinculação dos projetos com o sistema LEED (Liderança em Projeto de Energia e Ambiental) para o desenvolvimento de bairros. Isso significa considerar o papel das certificações que acompanham os processos de implementação dos projetos, segundo o Conselho da Edificação Sustentável dos Estados Unidos (USGBC).

Convém mencionar que, a partir da USGBC, estarão implícitos outros indicativos que auxiliam na demonstração do fenômeno da sustentabilidade como formadora de um mercado crescente para novos investimentos no setor da construção civil. Isso implica afirmar que as ações do New Urbanism, embora constituam demonstração elucidativa deste processo, não permitem captar a 
natureza holística e geral que um mercado pode abarcar, ainda mais se consideramos um contexto tão complexo como o dos Estados Unidos. O que se quer enfatizar é a dispersão continuada de projetos independentes por intermédio de inúmeros escritórios e empresas que se apropriam de uma ou outra forma das nuances vinculadas à matriz discursiva da sustentabilidade e, assim, o fazem principalmente na esfera da certificação da USGBC, cujas ações se ampliam para vários outros países, tendo por base suas respectivas sucursais como, por exemplo, a Green Building Council Brasil.

De acordo com Keller e Burke, o LEED se constitui em um certificado da USGBC que foi "criado com o objetivo de produzir um sistema de certificação nacional consensual voltado para o mercado, dedicado especialmente às edificações de alto desempenho" (2010, p.264). Os autores apresentam alguns números que demonstram, por meio das certificações, a evolução e a consolidação dos mercados verdes - e isso leva em conta a disseminação de estratégias empresariais, novas tecnologias e um mercado de trabalho especializado. Desde o surgimento do sistema LEED nos Estados Unidos até o ano de 2008, no que transcorreram 10 anos, 55 mil profissionais receberam títulos que lhes conferiam aptidão nas técnicas de edificação sustentável e, igualmente, aproximadamente 20 mil projetos estariam em vias de certificação ou à espera de resultados de avaliações técnicas até 2008 (KELLER; BURKE, 2010).

$\mathrm{Na}$ escala internacional o USGBC passou a ser instituído pelo Conselho Mundial de Edificações Sustentáveis (WGBC - Word Green Building Council), uma instituição gerida por líderes comerciais vinculados aos conselhos nacionais do Green Building. O perfil e grandeza dos mercados verdes também podem ser relativamente considerados segundo números da WGBC e da McGraw Hill Construction - gigante do setor da construção nos Estados Unidos. Em pesquisa desenvolvida em 2008, com base em 700 profissionais da indústria da construção civil em 45 países, constatou-se que 94\% das empresas adotarão até 2013 algum tipo de projeto ambientalmente sustentável, o que demonstra, no comparativo com o ano de 2003, um expressivo crescimento de quase $300 \%$. Tal aumento constitui um dado relevante, pois se associa com as expectativas que os empreendedores possuem ao vincular suas empresas às marcas "verdes", o que, segundo eles, amplia as perspectivas de lucro em tempo relativamente rápido, como pode ser verificado por $56 \%$ dos entrevistados. (MCGRAW HILL; WGBC, 2008)

Esses e outros números sinalizam, portanto, uma tendência que se revela na esfera econômica e urbana ao redor do mundo, conduzida por capitais crescentemente mais fluidos e livres para buscar seus canais de reinvestimento. No contexto da globalização neoliberal as possibilidades criadas com a temática da sustentabilidade também se tornam globais - e isso pode ser demonstrado pelos números da WCBG. Da mesma forma, outros padrões nacionais de certificação elucidam o teor global dos projetos sustentáveis, dentre eles o sistema japonês 
CASBEE, sigla em inglês para Sistema de Avaliação Abrangente para a Eficiência Ambiental de Edificações; o sistema BREEAM (Método de Avaliação Ambiental de Edificações), desenvolvido no Reino Unido; assim como o Green Star, na Austrália; o HKBEAM, em Hong Kong; o HQE, na França etc. Todos eles sistemas de certificação nacional similares ao USGBC, embora o BREEAM também tenha implicação internacional, sobretudo na Europa.

Dessa forma, ao observar os sistemas de certificação torna-se possível enxergar redes espaciais que começam a se configurar no âmbito global, por onde fluem ao mesmo tempo as correntes interpretativas incorporadas ao paradigma ambiental e a matriz dominante da sustentabilidade, e os anseios dos promotores privados associados à produção da cidade. Entende-se que o rol de medidas associadas às construções sustentáveis resulta de um mesmo movimento de fundo, ainda que os fundamentos por ele constituídos venham a ser posteriormente reinterpretados segundo diferentes contextos e visões. Em cada um dos países surgem diretrizes de orientação ao processo construtivo e, ao avaliar o leque de sistemas de certificação, é possível verificar preocupações que convergem essencialmente no grau de eficiência energética da edificação, no tipo de material utilizado, na gestão dos resíduos, além de outros elementos relativos à qualidade do ambiente interno; como também os sistemas de transporte, acessibilidade, inovação, níveis de ruído, o uso e a ocupação do terreno, dentre outros aspectos que, em conjunto, engendram um índice quantitativo de sustentabilidade. No caso do Green Building, por exemplo, confere-se uma certificação em quatro níveis - certificado, prata, ouro e platina -, de acordo com determinada pontuação obtida a partir de categorias atreladas ao projeto.

Nesse sentido, ao considerar a variedade de selos e certificados ambientais existentes e sua vinculação com os empreendimentos ao redor do mundo, estamos, a princípio, buscando levantar as evidências de como a questão ambiental altera e cria mercados no contexto atual da globalização. A despeito das considerações sobre o mercado da construção, esta mesma implicação deve ser apontada para as certificadoras enquanto entidades que instituem outro mercado que caminha em conjunto à indústria da construção e do ramo imobiliário. O que se busca enfatizar neste ponto é a gama variada de tipos de selos que surgem em resposta às necessidades específicas associadas ao projeto constitutivo, o que significa destacar certificadoras exclusivas para hospitais, escolas e indústrias, principalmente.

Dentre outras evidências relevantes à discussão, também é válido ressaltar elementos das cidades europeias, em que pese o teor dos empreendimentos certificados isolados, mas, da mesma forma, o que aqui se considera mais elucidativo para a presente discussão, a concepção relativa aos denominados Ecoquartiers - um termo em francês para designar empreendimentos em escalas de bairro ou de uma respectiva coletividade que ultrapassa o enfoque somente da edificação. Da mesma forma que o New Urbanism nos Estados Unidos, os 
Ecoquartiers imprimem uma marca que ganha atratividade crescente do setor da construção, como pode ser constatado na ampliação do número de projetos na França e em outros países europeus. Ou seja, a leitura do espaço urbano europeu a partir da década de 1990 deve perpassar pela investigação em torno dos Ecoquartiers, vislumbrado no âmbito da expansão urbana como elemento espacial que abriga os ideais da "cidade sustentável". Segundo Lefévre e Sabard (2009), estes bairros incorporam uma visão idealizada da cidade do futuro, em que todos os melhoramentos possíveis voltados ao bem-estar dos cidadãos devam ser levados em consideração. Nessa mesma linha de reflexão, o presidente da federação nacional de cidades médias francesas enxerga no Ecoquartier um modelo que "busca captar a dimensão holística da problemática ambiental, o que não se trata apenas em construir prédios "verdes" ou planejar uma ciclovia, mas responder aos diversos componentes implícitos ao desenvolvimento sustentável" (BROCBOURG, 2011, p. 5). Ele também faz uma constatação do crescimento dos Ecoquartiers no contexto urbano francês e demonstra que, em 2009, foram apresentados 160 novos projetos dessa natureza, ao passo que, em 2011, este número ampliou-se para 393. Isso revela uma adesão relativa por parte das prefeituras e empresários pela démarche EcoQuartiers e, mais importante, agrega novas evidências à compreensão de um território que se reconfigura nas engrenagens do imperativo ambiental.

Não obstante, o Ecoquartier não será a única evidência deste processo na Europa, onde a visibilidade adquirida pelo discurso sustentável é significativa tanto na esfera privada quanto na governamental, sobretudo por intermédio de marcos regulatórios urbanos associados à Comissão Europeia de desenvolvimento, mas também ao já mencionado ICLEI e outras organizações, como a Eurocities, o movimento Ecocités, o Conselho Europeu de Regiões e Municipalidades (CEMR Council of European Municipalitiesand Regions), a Organização de Cidades Unidas (UTO - United TownsOrganizations) etc.

Em adição, apenas com o objetivo de tecer algumas linhas sobre o cenário brasileiro, os agentes citados até aqui igualmente devem ser destacados na tentativa de caracterização dos indicativos espaciais de um mercado verde no Brasil. Mesmo longe de ser o único canal pelo qual o discurso ambiental penetra nas estratégias empresariais, a certificação do Green Building ao lado do certificado AQUA oferecem evidências consistentes da evolução desses mercados, tendo em vista 0 número de empreendimentos em processo ou com certificados efetivados. Segundo a Green Building Brasil, em março de 2012500 empreendimentos já possuíam registro no conselho, porém somente 44 tinham certificação LEED deferida, o que corresponde a 434 unidades acumuladas e quase 24 milhões de metros quadrados construídos. No caso do AQUA, existem 51 empreendimentos certificados no Brasil, dentre bairros, edifícios residenciais, comerciais, hospitalares e educacionais (FUNDAÇÃO VANZOLINI, 2012). Segundo Justus (2013), em 
matéria do $O$ Globo de outubro de 2011, os chamados prédios verdes serão quase metade dos lançamentos comerciais no Rio de Janeiro, em São Paulo e em Curitiba (RJ $-40,8 \%$ do total ou $144 \mathrm{mil} \mathrm{m}^{2 ;} \mathrm{SP}-47,2 \%$ do total ou $446,3 \mathrm{mil} \mathrm{m}^{2}$; CTB $48,3 \%$ do total ou 7,8 mil $\mathrm{m}^{2}$ ) e, ainda de acordo com a matéria, o Green Buildingjá ratificou um protocolo de entendimentos com o Comitê Olímpico Brasileiro a fim de que todas as obras dos jogos olímpicos sejam certificadas.

\section{Considerações Finais}

Portanto, em nível de finalização, deve ser enfatizado que esta exposição de determinadas evidências concernentes a diferentes contextos urbanos serve de amparo às reflexões conduzidas no decorrer deste artigo e sinaliza as práticas cada vez mais recorrentes que operam nos mercados associados à produção do espaço urbano. Tais práticas estarão vinculadas a um discurso relativamente consolidado e representam a tônica de muitos planejadores, empresários, prefeitos e outros agentes que compõem o cerne da "cidade sustentável". Desse discurso derivam, pelo menos em boa parte, as engrenagens que reacendem os alicerces da cidade contemporânea, tanto como lócus da criação e recriação, quanto de reprodução ideológica. A dimensão destas práticas que permeiam o território sinaliza um desafio imposto pela racionalidade ambiental, cujos significados suscitam à reflexão crítica do modo como tal racionalidade, na condição de paradigma, pode condicionar aquele território à luz de seus dilemas e contradições, seja transformando-o ou reproduzindo-o.

Parece claro que a noção de sustentabilidade implícita em seu discurso não promove mudanças substanciais no padrão de desenvolvimento atual, embora suas repercussões espaciais venham a ser cada vez mais crescentes. Na prática, o discurso engrena um sistema complexo de ações que interferem no espaço e influi dessa maneira na constituição de um conjunto de variabilidades nos modelos de intervenção "sustentáveis", de acordo com os diferentes agentes, tipos de projeto, suas escalas e finalidades.

Podemos considerar que, majoritariamente, o papel do agente privado imobiliário como aquele que captura do discurso hegemônico a importância da tecnologia ambiental e explora, do mesmo modo, a perspectiva avalizada por tal discurso de importância de novos investimentos privados como alicerce da sustentabilidade econômica que as cidades demandam, é necessário para o desenvolvimento urbano sustentável. Desse modo, sob uma mesma tacada, os agentes privados encontram canais para reabsorção do capital excedente e um instrumento de legitimação. Aqui, o resultado incide diretamente no território por meio de novos bairros, loteamentos e condomínios sustentáveis de escalas absolutamente variáveis, ao contrário das intervenções comportadas pelo poder 
público local, que podem abranger não somente o plano físico e territorial, mas também uma gama muito maior de ações. Apenas para reiterar, caberá ao poder local buscar um tipo de planejamento urbano para a sustentabilidade mediante alguns elementos como, o consenso e a participação popular; a reorientação de investimentos públicos a fim de buscar tecnologias mais limpas; a definição de políticas ambientais setoriais e/ou metropolitanas; a criação de projetos de mobilidade urbana; a busca de novos padrões de governança que priorizem os modelos de parceria com a iniciativa privada e que reforcem as decisões coletivas.

Convém enfatizar alguns pontos importantes a respeito das variabilidades espaciais implícitas nos projetos de intervenção, sobretudo no que tange ao poder local. O exercício da atividade pública em relação à gestão da agenda hegemônica se depara com um receituário cuja abrangência e a complexidade oferecem pouca praticidade e objetividade à ação governamental. Concebe-se uma estratégia argumentativa que, de um lado, releva as mais prementes demandas das sociedades urbanas e, de outro, justifica a necessidade de atuação do capital como agente financiador e fomentador de tais demandas, a partir de processos de inovação, criação de novos produtos, serviços, postos de trabalho etc. Assim, dentre as variabilidades de ações disponibilizadas ao poder local, a principal delas apontará para mecanismos que favoreçam a ação de capitais que investem em tecnologias sustentáveis, à luz, sempre reiterando, do que a agenda hegemônica respalda como tal. Já que aqui se engloba tudo, desde a crítica ambiental nascente nos movimentos sociais até as exigências do capital, excluindo, assim, a contradição e o conflito para dar espaço ao consenso, prevalecerá o objetivo que o modelo empreendedor já vinha imprimindo nas prefeituras, o de tornar a sustentabilidade um mecanismo competitivo ao expressar-se como mais uma vantagem comparativa e um qualificativo que passa a funcionar como logomarca que impulsiona a imagem da cidade. Dentre as tantas práticas que têm emergido a partir da agenda hegemônica da sustentabilidade, será a variabilidade intrínseca ao papel do agente privado e de suas relações com o poder público o foco prioritário das abordagens seguintes, uma vez que representa na escala local a reafirmação do paradigma ambiental como princípio organizador do território no século XXI.

Este adendo a respeito das variabilidades se faz necessário porque leva em conta as múltiplas interpretações que emergem com a propagação da matriz discursiva, que poderá ecoar ou não segundo as variadas concepções existentes na sociedade. Logo, surgem inúmeros tipos de intervenção, desde aquelas com alto potencial tecnológico promovidas pelo grande empreendedor imobiliário, até as pequenas intervenções em escala comunitária concebidas em determinadas organizações de bairro. Nesse sentido, a matriz interpretativa moldada pelo discurso hegemônico torna-se essencial para a compreensão de uma conformação territorial que vai se estabelecendo ao longo do tempo a partir dos seus canais de influência, na medida em que baseia múltiplos campos de ação social na cidade. Isso significa que o 
discurso hegemônico impulsiona um movimento dialético de produção do espaço, no qual as formas urbanas concebidas segundo seus princípios serão acompanhadas de outras que buscam, quando não negá-lo, adaptá-lo aos anseios e concepções que surgem no bojo da sociedade. $\mathrm{O}$ mais importante aqui é enfatizar que tal matriz hegemônica imprime mudanças no tecido urbano de modo a repercutir estes fragmentos em seu sistema interpretativo, o que, em última instância, constitui transformações que não representam um projeto estrutural de civilização, mas visões descentralizadas e imbuídas de determinações individuais a partir de objetivos variados.

\section{Bibliografia}

AGENDA 21. (1992) United Nations Conference on Environment \& Development. Disponível em: <www.un.org/esa/sustdev/documents/agenda21/english/Agenda21.pdf > Acessado. Acessado em: 01 set. 2012.

BANCO MUNDIAL. (1999) A strategic view of urban and local governement issues: implications for the Bank. Washington: The World Bank.

. (2000) Cities in transition: World Bank urban and local government

strategy. Washington: The World Bank - Infrastructure Group Urban Development.

BORJA, J; CASTELLS, M. (1997) Cities as political agents. In: Local and GlobalManagement of cities in the Information Age. London: Earthscan Publication, UNCHS.

BROC-BOURG, B. (2011) Une appetence croissante pour les écoquartiers. Revista Le Moniteurs, Ministère de l'ecologie dudevelopment durable, dês transports et du logement. Caderno suplementar Écoquartiers, p. 5.

COMISSÃO MUNDIAL SOBRE MEIO AMBIENTE E DESENVOLVIMENTO. (1991) O Nosso Futuro Comum. $2^{\text {a }}$ Ed. Rio de Janeiro: Editora Fundação Getúlio Vargas.

CONGRESS FOR THE NEW URBANISM. (2001) Charter of the New Urbanism. Disponível em: <www.cnu.org/charter> Acessado em: 04 out. 2012.

DEL RIO, V.; TREVOR, K. (2003) New Urbanism, dependência do automóvel, senso de comunidade. Um estudo comparativo de dois conjuntos residenciais na Califórnia. Portal Vitruvius, Arquitextos, $\mathrm{n}^{\circ}$ 42. Disponível em: <www.vitruvius.com.br/arquitextos/arq000/esp201>. Acessado em: 04 out. 2012. FUNDAÇÃO VANZOLINI. Empreendimentos certificados no processo Aqua. Disponível em: <www.vanzolini.org.br/conteudo_104.asp?cod_site=104\&id_menu=810>. Acessado em: 20 nov. 2012. 
GREEN BUILDING BRASIL. (2012) Green Building Council Brasil Construindo um futuro sustentável. Apresentação GBC - FEICON BATIMAT, março.

HARVEY, D. (2006) Do administrativismo ao empreendedorismo - a transformação da governança urbana no capitalismo tardio. In: __. A produção Capitalista do Espaço. São Paulo: Annablume, $2^{\text {a }}$ ed.

INTERNACIONAL COUNCIL FOR LOCAL ENVIRONMENTAL INICIATIVES. Soluções Locais para Desafios Globais: Conectando Líderes Acelerando Ações - Criando Soluções Pioneiras. Disponível em: <www.iclei.org/fileadmin/user_upload/documents/Global/About_ICLEI/brochures /ICLEI_info-brochure_portuguese-www.pdf>. Acessado em: 14 set. 2012.

. (2010) Strategic Plan 2010-2015 - Local Governments for Sustainability Preparing for Tomorrow. Disponível em:

<http://www.iclei.org/fileadmin/user_upload/documents/Global/About_ICLEI/ICL EI_Strategy_2010-2015.pdf>. Acessado em: 14 set. 2012 . (2006) 2006 Year in Review - Local action moves the world. Toronto: Iniciatives - ICLEI Anual Report.

JUSTUS, P. Prédios verdes são quase metade dos lançamentos comerciais em Rio, São Paulo e Curitiba até 2013. Portal de notícias O Globo, Outubro de 2011. Disponível em: <http://oglobo.globo.com/imoveis/predios-verdes-sao-quasemetade-dos-lancamentos-comerciais-em-rio-sao-paulo-curitiba-ate-20133080138>. Acessado em: 30 out. 2012.

KUHN, T. (2003) A Estrutura das Revoluções Científicas. $7^{\mathrm{a}}$ ed. São Paulo: Perspectiva.

LEFÉVRE, P.; SABARD, M. (2009) Les Écoquartiers: L'avenir de lavilledurable. Rennes: Apogée.

MCGRAW HILL CONSTRUCTION. (2008) Global Green Building Trends: Market Growth and Perspectives from around the World. World Green Building Council, Smarth Market Report.

MOFFAT, S; et. al. (2012) Eco Cities Guide - Ecological Cities as Economic Cities. Washington: The International Bank for Reconstruction and Development The World Bank.

OLIVEIRA. F. L. (2009) Sustentabilidade e competitividade: a agenda hegemônica para as cidades do século XXI. In: ACSELRAD, H. A duração das cidades: sustentabilidade e risco nas políticas urbanas. Rio de Janeiro: Lamparina. pp. 193218. 